\title{
O processo de elaboração de um glossário bilíngue de colocações da área médica: contribuições para tradutores e professores de língua inglesa
}

\author{
Fernanda Goulart Ritti Dias \\ Universidade Federal de Alagoas \\ fergoulart@hotmail.com
}

\begin{abstract}
Resumo
O objetivo deste estudo é apresentar o processo de elaboração de um glossário bilíngue (português-inglês) de colocações da área Médica, enfatizando a importância do conhecimento da terminologia adequada para o trabalho de tradução, revisão e ensino de língua inglesa. O estudo encontrou suporte teórico e metodológico na Linguística de Corpus, cujos principais pressupostos são a abordagem empírica na análise de dados e a visão probabilística da linguagem. Além disso, permite a investigação de grandes quantidades de dados por meio de ferramentas computacionais, por exemplo o WordSmith Tools. Para a execução do trabalho, foram compilados dois corpora, um em português e outro em inglês, com aproximadamente $85 \mathrm{mil}$ palavras cada. Os resultados da pesquisa mostraram que o uso de corpus na tarefa de versão é muito relevante, principalmente quando se trata de colocações de uma área de especialidade. Concluímos que apesar de não ser uma tarefa simples e requerer muito cuidado e dedicação em todas as etapas, a elaboração de glossários é extremamente útil para aqueles que trabalham com a língua inglesa.
\end{abstract}

Palavras-chave: Linguística de Corpus; glossário bilíngue; colocações; língua inglesa.

\begin{abstract}
The objective of the present study is to show the process of organization of a bilingual collocations glossary (Portuguese-English) in the medical field, emphasizing the importance of knowing the correct terminology for translating, revising and teaching English. Theoretical and methodological support was provided by Corpus Linguistics, which emphasizes the importance of empirical data analyses and views language as a probabilistic system. Besides, it allows the investigation of large quantity of data through computational tools, e.g. WordSmith Tools. Two corpora, one in Portuguese and one in English, with approximately 85.000 words each were compiled.
\end{abstract}


The results indicated that the use of corpus in inverted translation tasks is very important, especially when it deals with collocations of a specific field. We concluded that although the organization of a glossary is not an easy task and requires great care and dedication in all its steps, it is very useful for those who work with the English language.

Keywords: Corpus Linguistics; bilingual glossary; collocations; English language.

\section{Introdução}

Grande parte das pesquisas científicas produzidas mundialmente é publicada em língua inglesa. Assim, cada vez mais estudantes e profissionais, além da necessidade de possuir habilidade de leitura nessa língua, precisam redigir seus trabalhos em inglês para conseguir publicação internacional e, dessa forma, obter prestígio acadêmico. Porém, o desconhecimento linguístico é uma grande barreira enfrentada pela maioria desses indivíduos, inclusive os tradutores que, muitas vezes, também não possuem familiaridade com a quantidade enorme de termos técnicos que cada área exige.

O desconhecimento de expressões apropriadas ao contexto por parte desses profissionais pode tornar o texto ininteligível, visto que muitas vezes acabam por fazer a tradução literal das palavras.

O fato é que cada área de especialidade utiliza sua própria linguagem, constituída por termos destinados a estabelecer maior precisão conceitual, nem sempre evidente para outras comunidades lingüísticas. (...) Ainda que os dicionários especializados tragam uma definição ou uma explicação, não parecem se preocupar com a dificuldade na escolha certa da combinação de palavras (CASTANHO, 2004, p. 3).

Os grupos profissionais são, assim, identificados por meio dos textos técnicos e científicos, expressos por uma linguagem que os marca, de um modo convencionado culturalmente estabelecido (KRIEGER e FINATTO, 2004). Dessa forma, com o intuito de atender à necessidade de estudantes, de professores e de tradutores de diversas áreas do conhecimento, algumas pesquisas sobre a elaboração de 
glossários bilíngues com o apoio da Linguística de Corpus têm sido desenvolvidas no Brasil nos últimos anos.

Moraes (2005) elaborou uma proposta de glossário de colocações adverbiais (inglês-português) baseado em corpus. Carvalho (2007) apresentou uma metodologia para a elaboração de um glossário bilíngue com base em um corpus do domínio técnico-automobilístico. Costa Filho (2008) desenvolveu uma proposta de glossário bilíngue de termos utilizados na Teoria da Metáfora Conceitual. Navarro (2012) fez uma proposta de glossário bilíngue (inglês - português) de colocações da hotelaria, voltado às necessidades do tradutor. Seemann (2012) construiu um glossário bilíngue e bidirecional dos termos futebolísticos mais frequentes no par linguístico espanhol-português, usados rotineiramente na comunicação escrita.

Com o advento da Linguística de Corpus e o uso e exploração de corpora como metodologia de pesquisa, o levantamento de palavras e colocações se tornou maior e muito mais rápido. Os recursos eletrônicos disponíveis atualmente possibilitam a produção de glossários muito mais confiáveis em relação àqueles compilados antigamente, muitas vezes manualmente (ORENHA, 2004). De fato, examinar um corpus de um milhão de palavras pode parecer uma tarefa quase impossível para o ser humano, mas é algo que o computador faz em poucos segundos (BERBER SARDINHA, 1999).

Diante do exposto, o objetivo principal deste estudo é apresentar o processo de uma amostra de um glossário bilíngue (português-inglês) de colocações da área Médica, subárea Reumatologia, com enfoque em fibromialgia. Reumatologia é a área do conhecimento médico que se ocupa do estudo das doenças que acometem os tecidos conjuntivos. A fibromialgia é uma dessas doenças e refere-se a uma condição dolorosa generalizada e crônica.

Para a realização do nosso trabalho, dois corpora, um em português e um em inglês, cada um contendo aproximadamente $85 \mathrm{mil}$ palavras, foram compilados em formato eletrônico e posteriormente analisados por meio do programa computacional denominado WordSmith Tools. Esse programa coloca à disposição do analista uma série de recursos, os quais, se bem usados, são extremamente úteis e poderosos na análise de vários aspectos da linguagem (BERBER SARDINHA, 1999). 
Para maior confiabilidade e autenticidade dos dados, foram coletados apenas artigos científicos retirados de revistas especializadas e redigidos por profissionais da área nativos para ambas as línguas.

\section{Pressupostos teóricos}

A Linguística de Corpus é, segundo Teixeira (2004, p.34):

(...) uma metodologia de pesquisa específica em que a exploração da linguagem é feita por meio de evidências empíricas extraídas, por meio do uso de ferramentas computacionais, de um corpus de linguagem natural/ autêntica, criteriosamente compilado e consultável eletronicamente.

Muitos pesquisadores dedicaram-se à descrição da linguagem por meio de corpora no início do século XX, entre eles educadores como Thorndike e linguistas, a exemplo de Boas e Fries. A grande diferença entre essa época e hoje é que os corpora não eram eletrônicos, ou seja, eram coletados, mantidos e analisados manualmente. Além disso, a ênfase era dada ao ensino de línguas, e não à descrição da linguagem, como atualmente, embora ainda haja o interesse no emprego de corpora na sala de aula e na investigação da linguagem de alunos de língua (BERBER SARDINHA, 2004).

A Linguística de Corpus requer o uso de um corpus. Segundo Bowker e Pearson (2002, p.9), "um corpus é simplesmente um corpo de texto". No entanto, no contexto da Linguística de Corpus, "o corpus pode ser descrito como uma ampla coletânea de textos autênticos coletados em formato eletrônico de acordo com um critério específico". Os textos devem ser selecionados de acordo com um critério explícito para que possam ser utilizados como uma amostra representativa de uma língua em particular. O critério utilizado para elaborar um corpus dependerá do propósito do estudo" (id. ibid., p. $10)$.

Outra importante área do conhecimento utilizada para a elaboração de glossários é a Terminologia, que "diz respeito à investigação das propriedades linguísticas, conceituais e pragmáticas 
das unidades terminológicas com vistas à produção de dicionários técnicos e científicos" (BESSÉ ET ALII, apud Krieger e Finatto, 2004, p.130).

Ao apoiar-se cada vez mais na Linguística, a Terminologia tem oferecido fundamentos teóricos que auxiliam no reconhecimento dos termos e na análise de seu comportamento nas diferentes línguas. Com isso, oferece aos tradutores uma compreensão mais clara sobre a natureza, o estatuto, a constituição e o funcionamento dos termos técnico-científicos (KRIEGER e FINATTO, 2004).

A Terminologia tem como campo de atuação as línguas de especialidade e a sua unidade padrão é o termo (BARROS, 2004). A identificação de um termo costuma ser problemática para os tradutores, uma vez que sua estruturação apresenta unidades lexicais complexas. Além disso, não é fácil demarcar as fronteiras rígidas entre o léxico especializado e o geral (KRIEGER e FINATTO, 2004).

Em um dicionário de língua geral, encontramos somente o vocabulário "técnico" de base de grandes áreas especializadas, ao passo que em um dicionário terminológico são empregados os termos mais específicos da área.

\subsection{As colocações}

O termo colocação foi originalmente introduzido pelo linguista J. R. Firth para descrever o fato de algumas palavras "andarem juntas", produzindo um discurso natural, tanto falado quanto escrito (MORAES, 2005).

Segundo Tagnin (2005), não há, via de regra, explicação para o fato de certas palavras combinarem-se com tal naturalidade. É o uso que consagra a maneira a serem utilizadas na língua. Um exemplo básico e simples citado pela autora é cão e gato. Por que não ocorre cachorro e gato? Simplesmente porque o uso consagrou cão e gato e não cachorro e gato nessa colocação.

Às vezes, só saberemos que uma combinação é uma colocação quando, ao procurarmos certa palavra em diversos dicionários, descobrirmos que todos eles, ou pelo menos a grande maioria, apresenta a mesma combinação. Em alguns casos pode ocorrer mais de uma opção, mas sempre dentro do mesmo campo semântico. Em português temos o caso de 'coroca', que, preferencialmente ocorre com 
'velha' (velha coroca); e de 'varrido', que ocorre com 'louco' ou 'doido’ (louco/doido varrido) (id. ibid., p. 37-38).

As categorias de colocações expostas pela autora são: colocações adjetivas (amigo íntimo), colocações nominais (cartão de crédito), colocações verbais (marcar um encontro) e colocações adverbiais (amar cegamente).

\section{Metodologia da pesquisa}

Primeiramente, construímos uma árvore de domínio, ou seja, uma organização semântica da área-objeto a fim de delimitar o conjunto terminológico e determinar a pertinência dos termos. Na Figura 1, apresentamos uma amostra da árvore de domínio realizada na nossa pesquisa.

Figura 1. Amostra da árvore de domínio

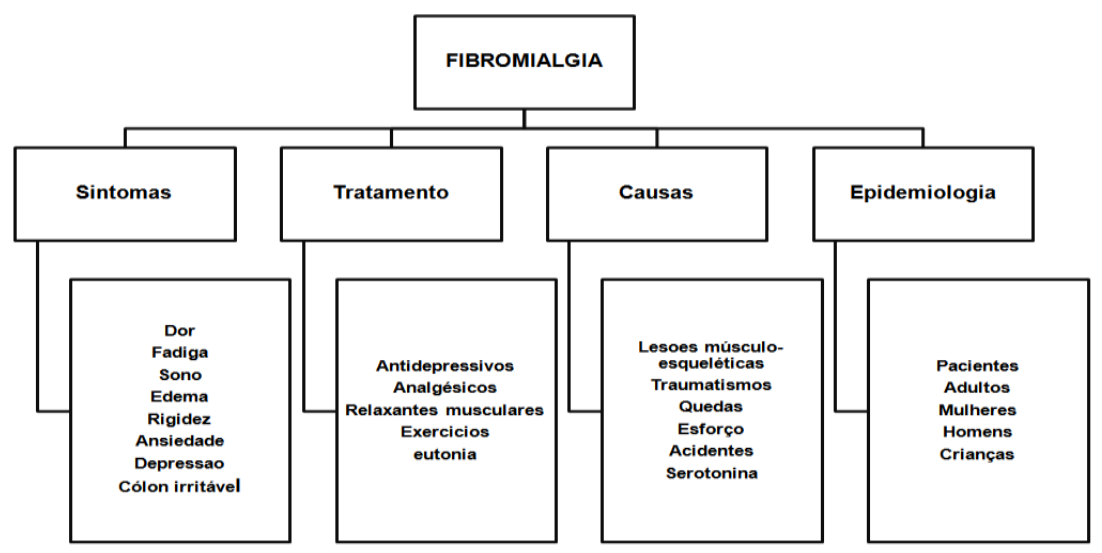

Dividimos nosso trabalho em seis etapas:

1. Busca dos corpora na web.

2. Colocação dos cabeçalhos e etiquetas necessárias.

3. Produção da lista de palavras-chave de ambos os corpora, (com a utilização do programa WordSmith 
Tools) obtida por meio da comparação da frequência da lista de palavras do corpus de estudo com a frequência da lista de palavras dos corpus de referência.

4. Levantamento das palavras-chave de conteúdo de cada lista.

5. Extração das colocações por meio da ferramenta Concord do WordSmith Tools e pela lista de Clusters.

6. Compilação do glossário.

\subsection{Coleta e armazenamento dos corpora}

A metodologia empregada na pesquisa constituiu-se da coleta de dois corpora: um em português e outro em inglês, cada um contendo, aproximadamente, 85 mil palavras. Em vista dos objetivos deste estudo, selecionamos textos autênticos, redigidos por especialistas da área Médica, retirados de sites confiáveis e consagrados da área.

A seleção dos textos seguiu os seguintes critérios de coleta:

1. Somente artigos científicos originais completos que se tratavam do tema fibromialgia, produzidos por falantes nativos de cada uma das línguas escolhidas.

2. Textos disponíveis eletronicamente em sites confiáveis. A busca dos textos na língua inglesa foi feita somente no site www.pubmed.com, um site em inglês que ajuda a realizar pesquisas bibliográficas por meio do acesso à base bibliográfica MedLine, desenvolvida pela NLM (National Library of Medicine) e que conta com mais de 12 milhões de citações. Já a busca dos textos em português foi feita no site www.scielo.br, uma biblioteca eletrônica que abrange uma coleção selecionada de periódicos científicos brasileiros.

3. Para uma boa análise, optamos por conseguir um número aproximado de palavras em cada corpora, o que, conforme citado anteriormente, totaliza $85 \mathrm{mil}$.

4. O ano de publicação dos textos também recebeu atenção durante a coleta. Escolhemos textos 
publicados somente entre 2000 e 2006. A comparabilidade dos corpora é apresentada na tabela 1.

Tabela 1. Características gerais dos corpora comparáveis

\begin{tabular}{lll}
\hline & Língua Portuguesa & Língua Inglesa \\
\hline Tamanho & 84.708 & 85.199 palavras \\
Número de textos & 21 & 20 \\
Meio & Escritos & Escritos \\
Fonte & www.scielo.br & www.pubmed.com \\
$\begin{array}{l}\text { Assunto } \\
\text { Gênero textual }\end{array}$ & Fibromialgia & Fibromialgia \\
& Artigos científicos & $\begin{array}{l}\text { Artigos científicos } \\
\text { completos }\end{array}$ \\
$\begin{array}{l}\text { Autoria } \\
\text { Língua } \\
\text { Data de } \\
\text { publicação }\end{array}$ & Autores nativos & Autores nativos \\
\hline
\end{tabular}

Os textos encontrados foram separados por língua, colocados em arquivos no computador e nomeados com um código, (por exemplo, FIB1P, quando em português; e FIB1E, quando em inglês.). Para armazená-los, utilizamos o Bloco de Notas do Windows, que grava os textos automaticamente em .txt,. Esse tipo de arquivo é requerido pelo Wordsmith Tools, o qual, por sua vez, foi nossa ferramenta de análise do corpus.

Em cada texto foi inserido um cabeçalho, que é parte do arquivo de cada texto do corpus que contém informações sobre o texto, tais como a origem, a data de coleta, a autoria, entre outras.

\subsection{Análise dos corpora}

Para a construção do nosso trabalho, utilizamos a "versão 3" do programa WordSmith Tools, disponível no site http://www.lexically.net/wordsmith/.

As ferramentas do programa utilizadas foram as seguintes: 1Wordlist (lista de palavras individuais); 2-KeyWords (lista de palavraschave) e 3- Concord (concordância; lista de agrupamentos lexicaisclusters. Primeiramente, fizemos uma lista de palavras, e, em seguida, a lista de palavras-chave de cada corpora de estudo. 
Para a pesquisa e montagem da lista de palavras-chave do nosso corpus, utilizamos dois corpora de língua geral como referência: em inglês, o Brown Corpus $^{l}$, que possui textos escritos em inglês americano e possui um milhão de palavras. Para os textos em português, utilizamos o Corpus Lacio-Ref, que disponibiliza um conjunto de textos escritos autênticos do português brasileiro e possui 4.156.816 palavras.

Com base na lista de palavras-chave do corpus de línguas portuguesa, selecionamos as palavras que ocorreram com maior frequência e iniciamos a busca de colocações. Com a ferramenta Concord do WordSmith Tools, obtivemos as listas de concordâncias (Figura 2). Encontradas as concordâncias na língua portuguesa, passamos a buscar as concordâncias equivalentes na língua inglesa.

Encontradas as concordâncias, iniciamos a organização do glossário, que será apresentada na próxima seção.

\section{Resultados e discussão}

Com base na lista de palavras-chave do corpus em língua portuguesa, foram gerados 21 termos-chave: ansiedade, depressão, diagnóstico, distúrbio, dor, eutonia, exercício, fadiga, fibromialgia, hepatite, melhora, mulher, paciente, percepção, prevalência, qualidade, sindrome, sintoma, sintomatologia, sono e tratamento.

A partir desses 21 substantivos, foram geradas 53 colocações. Ressaltamos que foram selecionadas as colocações mais frequentes do corpus de estudo, e não um tipo específico de colocação, ou seja, verbal, nominal, etc.

O objetivo era encontrar todos os termos dentro do corpus de estudo, porém, isso nem sempre foi possível. Durante a busca das colocações, não encontramos três equivalentes na língua inglesa (Efeito da eutonia, Prevalência de dor crônica difusa e Síndrome do cólon irritável). Diante de tal limitação, optamos por buscá-las no site www.google.com.br, de modo a verificar a origem e a autenticidade dos textos sempre, além de garantirmos se o termo pertencia a textos

\footnotetext{
${ }^{1}$ Outro corpora de referência em língua inglesa que tem sido bastante utilizado por pesquisadores da área é o British National Corpus (BNC).
} 
sobre fibromialgia. As três colocações buscadas na internet foram encontradas no site PUBMED, utilizado no início da pesquisa, o que garantiu mais segurança quanto às colocações encontradas.

\section{Figura 2. Exemplo de lista de concordância com termo de busca "pacientes"}

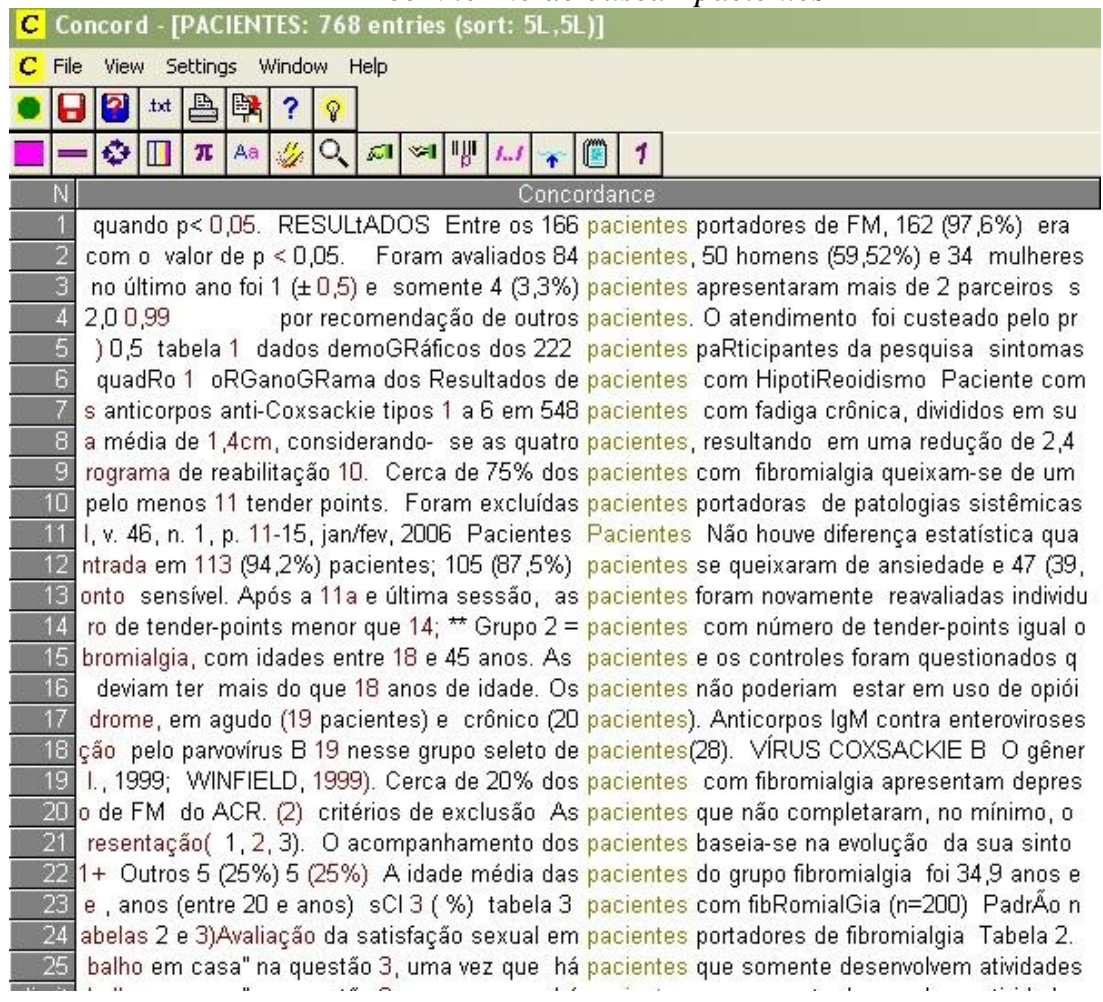

No quadro 1, apresentamos as colocações que apresentam preposições, o que parece ser uma das maiores dificuldades para quem trabalha com produção textual em língua estrangeira. As preposições $d a$, do e de, em português, que têm a tendência de serem traduzidas como of em inglês, foram aqui apresentadas como of, in, ou até sem a preposição. 
Quadro 1. Colocações com a preposição "de"

\section{Colocações com a preposição of}

Diagnostico de fibromialgia - Diagnosis of fibromyalgia

Distúrbio de dor - Disturbance of pain

Presença de dor-Presence of pain

Prevalência de depressão - Prevalence of depression

Prevalência de dor crônica difusa - Prevalence of chronic widespread pain

Qualidade de vida - Quality of life

Qualidade do sono - Quality of sleep

Tratamento da fibromialgia - Treatment of fibromyalgia

\section{Colocações com a preposição in}

Alterações do sono - Alterations in sleep

Melhora da dor - Improvement in pain

Melhora da qualidade de vida - Improvement in quality of life

Redução da sintomatologia - Reduction in symptoms

\section{Colocações sem preposição}

Distúrbio do sono - Sleep disturbance

Efeito da eutonia - Eutonia effect

Escores de depressão - Depression scores

Intensidade da dor - Pain intensity

Melhora da sintomatologia - Symptom improvement

Pacientes do sexo feminino - Female patient

Percepção da dor - Pain perception

Programas de exercícios - Exercise program

Síndrome da fadiga crônica - Chronic fatigue syndrome

Síndrome da fibromialgia - Fibromyalgia syndrome

Síndrome do cólon irritável - Irritable bowel syndrome

Sintomas da dor - Pain symptoms

Sintomas da fibromialgia - fibromyalgia symptoms

Vírus da hepatite $\mathrm{C}-$ Hepatitis $C$ virus

Também encontramos a preposição com, com equivalentes a exemplo de with ou simplesmente sem a preposição (quadro 2).

Diante disso, não restam dúvidas quanto à importância do levantamento das colocações em outra língua por meio de corpora eletrônico. Ficou claro que, quando se trata de colocações, deve-se ter cuidado dobrado, pois nem tudo o que parece é. Assim, usuários de 
uma determinada língua estrangeira, neste caso a língua inglesa, devem buscar obras que atendam à busca por soluções tradutórias para as colocações, haja vista que a maioria dos dicionários técnicos e especializados existentes não apresentam a forma consagrada que essas colocações se apresentam. De fato, segundo Tagnin (2005), às vezes só percebemos que uma combinação é uma colocação quando vários dicionários apresentam determinadas palavras da mesma forma.

Quadro 2. Colocações com a preposição "com"

\section{Colocações com a preposição with}

Mulheres com fibromialgia - Women with fibromyalgia

Pacientes com fibromialgia - Patients with fibromyalgia

Pacientes com síndrome da fibromialgia - Patients with fibromyalgia syndrome

\section{Colocação sem preposição}

Pacientes com dor crônica - Chronic pain patients

A preposição na também merece destaque, já que teve por equivalentes on e in (quadro 3).

Quadro 3. Colocações com a preposição "na"

\section{Colocações com as preposições on e in}

Impacto na qualidade de vida - Impact on quality of life

Melhora na qualidade de vida - Improvement in quality of life

É possível, pois, afirmar que a consciência da convencionalidade de uma língua é fator crucial para que uma comunicação ou tradução seja fluente e efetiva. A falta dessa consciência pode, sem dúvida, "comprometer transações de negócios, pelo simples motivo de não seguir regras composicionais e convencionais ditadas pela língua" (ORENHA, 2004, p. 2).

\subsection{A organização do glossário}

Ressaltamos novamente que nosso propósito foi mostrar como se dá o processo de elaboração de uma amostra glossário técnico de 
colocações. Dessa forma, apenas uma pequena amostra do glossário será apresentada.

Os termos retirados da lista de palavras-chave, ou seja, os substantivos formaram as bases das colocações, e, portanto, foram dispostos em ordem alfabética e no singular. Além disso, foram destacados e sublinhados para facilitar a busca do consulente. Dentro de cada base, foram apresentadas as entradas, ou seja, as colocações que fazem referência ao respectivo substantivo de base, as quais também foram organizadas alfabeticamente.

Embora não tenhamos apresentado, em nossa pequena amostra, informações etimológicas, ortográficas, fonéticas ou gramaticais sobre as entradas, sabemos de sua importância para aqueles que trabalham com a produção textual. Definições ou explicações sobre as entradas também não foram fornecidas em nossa amostra. De fato, segundo Barros (2004, p.145), a principal característica de um glossário "é não apresentar definições, mas tãosomente uma lista de unidades lexicais ou terminológicas acompanhadas de seus equivalentes em outras línguas".

Os equivalentes na língua de chegada seguem as colocações referentes ao substantivo base e podem ser lidos horizontalmente. Abaixo das colocações foram fornecidos exemplos em ambas línguas, e não a tradução dos mesmos, retirados do nosso corpus de estudo com a ajuda da ferramenta concord. Em cada exemplo, as colocações foram destacadas para melhor visualização.

A tabela 2 apresenta uma pequena amostra da organização do glossário. Selecionamos alguns exemplos da letra "D".

\section{Considerações finais}

O computador e a linguística, aliados, têm trazido inúmeros benefícios para estudiosos da área. Inúmeras tarefas, de diversas áreas do saber, antes impossíveis ou difíceis de serem realizadas, tornaramse possíveis e mais rápidas. A ferramenta computacional WordSmith Tools, dotada de inúmero recursos, realiza etapas essenciais para a compilação de glossários e dicionários, que jamais poderiam ser feitas manualmente com tanta eficácia, precisão e em tão pouco tempo. 
$\underline{\mathbf{D}}$

\section{DEPRESSÃO}

ANSIEDADE E DEPRESSÃO

A influência do estilo de vida no desenvolvimento de ansiedade e depressão é comprovada.

\section{ESCORES DE DEPRESSÃO}

Relação entre a percepção da saúde versus os escores de depressão.

\section{PREVALÊNCIA DE DEPRESSÃO}

Neste estudo, buscou-se descrever a relação entre a prevalência de depressão e sua relação com a qualidade de vida nos pacientes com fibromialgia.

\section{DEPRESSION}

ANXIETY AND DEPRESSION

Anxiety and depression are associated with the reporting of greater subjective pain.

DEPRESSION SCORES

Unexpectedly, serum serotonin levels rose correspondingly with depression scores, contrary to what has been reported in clinic patients. PREVALENCE OF DEPRESSION

Finally, an increased prevalence of depression has been found in patients with fibromyalgia.

É claro que a contribuição do linguista é de extrema importância no processo, pois é ele quem seleciona os textos a serem inseridos no corpus e analisa os termos que serão inclusos na obra de referência. Ressaltamos que se essas etapas não forem executadas com muito critério, podem, sem dúvida, afetar o produto final.

A experiência obtida durante a compilação de uma amostra de glossário bilíngue ratifica essas afirmações. A coleta, o armazenamento dos textos e a seleção das colocações que compuseram nosso glossário foram as etapas mais trabalhosas e que mereceram mais atenção. No entanto, sem a ajuda do computador, em especial da internet, que 
disponibiliza textos autênticos e de diversas áreas do saber, o trabalho não poderia ter sido iniciado.

Em geral, o principal objetivo do trabalho, descrever o processo que compõe a elaboração de um glossário bilíngue com base na Linguística de Corpus, foi realizado. Também foi possível mostrar as peculiaridades das colocações e, consequentemente, sua importância para os que trabalham com produção de texto em língua inglesa. Ficou claro que o uso de corpus na tarefa de versão é muito relevante, principalmente quando se trata de colocações de uma área de especialidade. Além disso, quanto maior o corpus de estudo, mais eficaz se torna a busca das colocações. Por isso, a tarefa de elaboração de um glossário não é tarefa fácil e requer muito cuidado e dedicação em todas as etapas.

\section{Referências}

BARROS, Lidia Almeida. Curso básico de terminologia. Edusp, 2004.

BERBER SARDINHA, Tony. Usando WordSmith Tools na investigação da linguagem. DIRECT papers 40, 1999. Disponível em: http://www2.lael.pucsp.br/direct/direct_papers.htm. Acesso em $10 \mathrm{dez}$. 2005.

A influência do tamanho do corpus de referência na obtenção de palavras-chave. DIRECT papers, 38, 1999. Disponível em: <http://www2.lael.pucsp.br/direct/direct_papers.htm> . Acesso em 8 dez. 2005.

. O banco de palavras chave. LAEL, PUCSP. DIRECT Papers, 39, $1999 . \quad$ Disponível em: <http://www2.lael.pucsp.br/direct/direct_papers.htm>. Acesso em 8 dez. 2005.

. Linguística de Corpus. Barueri, SP: Manole, 2004.

BOWKER, Lynne; PEARSON, Jennifer. Working with specialized language. London/New York: Routledge, 2002. 
CARVALHO, Estela Maria Faustino. Metodologia de construção de um Glossário bilíngüe com base em um corpus de Domínio técnico. 2007. 80f. Dissertação (Mestrado em Estudos da Tradução). Centro de Comunicação e Expressão. Universidade Federal de Santa Catarina, Florianópolis, 2007.

CASTANHO, Rosa Maria. Proposta para a Elaboração de um Glossário de Colocações na Área Médica. Subárea Hipertensão Arterial. 2004. 92p. - Dissertação. (Mestrado em Estudos Linguísticos e Literários em Inglês) - Departamento de Letras Modernas da Faculdade de Filosofia, Letras e Ciências Humanas da Universidade de São Paulo, São Paulo, 2004.

COSTA FILHO, José Edelberto. Elementos para um glossário bilíngüe (português e inglês) de termos-chave da Teoria da Metáfora Conceitual.2008.148f. Dissertação (Mestrado em Linguística Aplicada). Departamento de Letras. Universidade Estadual do Ceará, Fortaleza, 2008.

KRIEGER, Maria da Graça; FINATTO, Maria José Bocorny. Introdução à terminologia. Ed. Contexto, 2004.

MORAES, Helmara Febeliana Real de. O tradutor pode estar redondamente enganado: um estudo contrastivo de colocações adverbiais (inglês-português) sob o enfoque da linguística de corpus. 2005. Dissertação. 207p. (Mestrado em Letras). Faculdade de Filosofia, Letras e Ciências Humanas da Universidade de São Paulo, São Paulo, 2005.

NAVARRO, Sandra Lago Martinez. Glossário bilíngue de colocações de hotelaria: um modelo à luz da Linguística de Corpus. 2011. Dissertação (Mestrado em Estudos Lingüísticos e Literários em Inglês) - Faculdade de Filosofia, Letras e Ciências Humanas, Universidade de São Paulo, São Paulo, 2012.

ORENHA, Adriane. A compilação de um glossário bilíngüe de colocações, na área de Jornalismo de Negócios, baseado em corpus comparável. 2004. 246 f. Dissertação (Mestrado em Estudos 
Linguísticos e Literários), Faculdade de Letras e Ciências Humanas, Universidade de São Paulo, São Paulo, 2004.

Aplicações léxico-terminográficas da linguística de corpus: relato da elaboração de um glossário bilíngue de colocações na área de negócios. Intercâmbio, v. 13, n. 1, 2004. Disponível em: http://revistas.pucsp.br/index.php/intercambio/article/view/3992. Acesso em 20 jan. 2007.

SEEMANN, Paulo Augusto Almeida. A construção de um glossário bilíngue de futebol com o apoio da Linguística de Corpus. 2012. 228 f. Dissertação (Mestrado em Língua Espanhola e Literaturas Espanhola e Hispano-Americana) - Faculdade de Filosofia, Letras e Ciências Humanas, Universidade de São Paulo, São Paulo, 2012.

TAGNIN, Stella Esther Ortweiler. O jeito que a gente diz: expressões convencionais e idiomáticas. São Paulo: Disal, 2005.

TEIXEIRA, Elisa Duarte. Receita qualquer um traduz. Será? A Culinária como área técnica de tradução. 2004. Dissertação (Mestrado em Estudos Linguísticos e Literários em Inglês) -Faculdade de Filosofia, Letras e Ciências Humanas, Universidade de São Paulo, São Paulo, 2v, 2004.

Recebido em: 16/09/2011

Aceito em: $\quad 01 / 10 / 2012$

Title: The process of organization of a bilingual collocations glossary in the medical field: contributions for translators and English teachers 
O processo de elaboração de um glossário bilíngue

$170 \quad$ Horizontes de Linguística Aplicada, ano 10, n. 2, jul./dez. 2011 